\title{
Perspectives on gender parity in bioanalysis: an interview with Stephanie Cape
}

\author{
Stephanie Cape ${ }^{*, 1}$ \\ ${ }^{1}$ Bioanalytical Chemistry, Covance Laboratories, 3301 Kinsman Blvd, Madison, WI 53704, USA \\ *Author for correspondence: stephanie.cape@covance.com
}

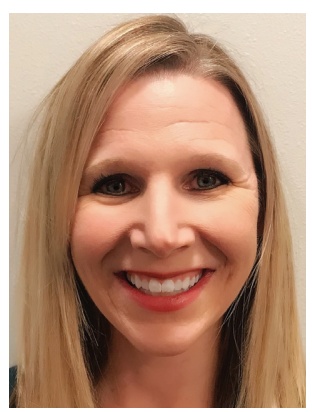

\section{Biography:}

Stephanie Cape, is the Director of Bioanalytical Science at Covance, Madison, WI, USA. She received her BS in Chemistry from University of IL- Urbana/Champaign in 2003 and her PhD in Analytical Chemistry from the University of Wisconsin - Madison in 2007. Dr Cape's graduate research was focused on developing high-resolution mass spectrometric methods to enable discovery, characterization, imaging and quantitation of neuropeptides. Stephanie joined the field of regulated bioanalysis as a method development/validation chemist initially at PPD and subsequently at Covance. Within the Covance Bioanalytical team, she has held a variety of leadership roles including oversight of bioanalytical study direction, validation and method development. Additionally, Dr Cape is an active member of the broader scientific community through involvement in multiple industry groups focused on global best practices and innovation in the field of bioanalysis.

Accepted for publication: 5 March 2019; Published online: 18 April 2019

\section{How can mentors help women in their career development?}

It is important for women in STEM to have coaches that are open and honest. These coaches can advise on how to position and make the right connections to build a strong network of relationships within the scientific community throughout all stages of career development. It is also key that these coaches recognize the importance of helping women learn to build confidence by embracing their strengths so that they can successfully advocate and negotiate for themselves.

\section{How important it is to have short term \& long-term goals in your career?}

For me, short-term goals are essential to making sure that I feel engaged. I find that sometimes, I need to consciously push outside of my comfort zone and challenge myself in order to learn and grow. Setting and achieving short-term goals that are aligned with my long-term aspirations ensures that I stay on the path toward my overall vision. In our industry, performance-driven cultures reward those who are focused on continuous improvement. Those who proactively prepare for the next level are often looked to when opportunities arise.

\section{What advice would you give to women hoping to pursue senior-level scientific positions?}

Think about the skill sets that you will need to position you for those roles. What are your strengths? What energizes and engages you? What opportunities are available to you now that can help you to gain different experiences and build these skills? I think it is important to consider that it may not be a direct route and that there are a variety of skills including technical and soft skills that are key to success in these positions.

\section{What are the most valuable skill sets women/diversity bring to an organization?}

Today's science is highly interdisciplinary and collaborative. The problems are complex and difficult to solve. If we are going to succeed, it is critical that we must work as a team and we need that team to be made up of a variety of individuals with different backgrounds, perspectives and training. A diverse group working in an open and collaborative environment will feel comfortable to propose and challenge creative ideas resulting in the best solution. 


\section{What are the main motivations for you in the industry as a woman?}

My motivations are heavily people oriented. For me, as for most of the people in this industry, it is personal. I know that the work that I do each day supports the development of life-changing treatments. I work so that someday the illnesses that have taken our loved ones much too soon will be distant memories prevented by vaccines or curable through innovative medicines. I am also motivated by my colleagues and my team. They are talented, hardworking and operate with incredible focus and integrity. It is important for me to position my team to achieve success on their projects and in their careers. I am also strongly motivated by my family. Although my 9-year-old son thinks he is going to be a professional baseball player when he grows up, my husband and I agree that it is probably a good idea to have a college savings account as a back-up plan. Working in this industry allows me to apply my skillset as a leader and a scientist to help people and also importantly to make money doing so.

\section{How do you mange work/life balance in your busy schedule \& what advice would you like to} give to young women who are starting their careers?

In my experience, work/life balance does not happen on a daily basis, but it does happen on a broader scale. I have no illusion that I am going to make it home for dinner every night, but I also know that if I work late to ensure a critical deadline is met, I may choose to leave early another day to take my son to the park after school. I know I need to put in extra time before taking a vacation, but I then log-off during my vacation and focus on my family. For me, work/life balance is about being in the moment and focusing on quality not quantity. As I have matured in my career, I have learned how to strike a balance that is successful for me and my family. Balance will mean different things to different people depending on individual family situations, career goals and aspirations and this will also change throughout stages of life.

\section{Disclaimer}

The opinions expressed in this interview are those of the interviewee and do not necessarily reflect the views of Future Science Group.

Financial \& competing interests disclosure

The author has no relevant affiliations or financial involvement with any organization or entity with a financial interest in or financial conflict with the subject matter or materials discussed in the manuscript. This includes employment, consultancies, honoraria, stock ownership or options, expert testimony, grants or patents received or pending, or royalties.

No writing assistance was utilized in the production of this manuscript. 